\title{
Pattern of Internet Usage at the Rural Library among Rural Youth in Malaysia
}

\author{
1Siti Zobidah Omar \\ 1Raidah Mazuki \\ 2Jusang Bolong \\ 1Jeffrey Lawrence D'Silva \\ ${ }^{1}$ Hayrol Azril Mohamed Shaffril \\ ${ }^{1}$ Institute for Social Science Studies, Universiti Putra Malaysia \\ ${ }^{2}$ Faculty of Modern Language and Communication, Universiti Putra Malaysia
}

\author{
Doi:10.5901/mjss.2016.v7n1s1p91
}

\section{Abstract}

The main aim of this study is to identify the pattern of Internet usage at the rural library among rural youths in Malaysia (aged between 15 to 40 years old). As a developing country, the internet usage among rural youths is a crucial issue in terms of the digital divide between rural and urban youths. The study was quantitative in nature, and via a multi-stage simple-random sampling, a total of 400 rural library users from four selected districts had been selected as the respondents. The SPSS software was used to run a proper analysis. The results showed that the mean score recorded for internet usage among the rural youths was 91.12 minutes and the majority of them were aged below 20 years old. Remarkably, the local development is seen as the motivation for the rural youths, yet it is probably the least manageable. Recommendations for future research and implications for practice are presented in the conclusion.

Keywords: internet usage, rural library, rural youth, pattern of internet usage.

\section{Introduction}

\subsection{Internet usage}

The Malaysian Institute of Microelectronic Systems (MIMOS) was responsible in introducing the Internet in Malaysia in 1987 through its RangKom (Rangkaian Komputer Malaysia or Malaysia Computer Network) project. As the experiment RangKom with the associates with several universities in Malaysia was successful and it was turned into an Internet Service Provider offering services to a limited number of members of the public in 1991. MIMOS launched Malaysia's first Internet Service Provider (ISP) called JARING in the subsequent years. Now, there were nine ISPs in Malaysia. The Internet has been a fundamental new technology within a community, including the rural community. In a rural area community, the Internet was selected to show how an ICT innovation diffused. The government plays a major role in engaging the use of the internet via various initiatives. As Malaysia is seen as a model for the third world countries', it may stimulate others for the ICTs' development (Ali and Mohd, 2011). A lot of them are currently using this advanced technology to help improve their knowledge and search for current issues about the world. Other than that, the Internet has been used to aid in teaching, doing research and also for cooking. Consequently, it gives impact to the rapid changes in the environment. Moreover, the Internet has the power to minimize space and time but it cannot substitute the human cognitive abilities (Drucker, 2001). Somehow, the Internet offers better opportunity for the community in reaching a sustainable and a competitive improvement by minimizing the cost and time (Vongchavalitkul et al., 2005).

Furthermore, in terms of a learning process, Rudenstine, (1996) noted that the Internet has the advantages as it becomes a medium that allows students the access to information for higher learning purposes, especially the access to information regarding course material constructions and conversational learning support. According to Korgaonkar and Wolin (1999), the Internet has unique features such as escapism, information control, interactive control (facilitate in managing the presentation of information), socialization, and economic motivation which was differentiated by the light (less than an hour per day) and heavy Web users. Hence, there is an abundance of advantages for using the Internet in order to achieve a knowledgeable Malaysian society in the year of 2020. 


\subsection{Rural Youth and Rural Library}

The rural community faces a problem in confronting globalization and technological change. The rural library was operating as a place for reading, seeking of information and knowledge, and organizing discussions. This project is an attempt derived from the National Library of Malaysia (NLM), which is under the jurisdiction of the Information, Communication and Culture Ministry. The management of rural library is fully funded by NLM in order to reduce the digital and knowledge divide between the urban and the rural communities. In relation to that, youths and children make up the majority of rural library users. Reading materials such as novels, educational materials, books, magazines and newspapers are among the attracted main resources in rural libraries (Omar et al., 2012). Omar et al. (2012) also indicates that education materials are in high demand before and during major examinations such as UPSR (Malaysia Primary School Certificates), PMR, SPM and STPM.

On top of that, in recent years, the rural library has been equipped with computers and Internet services provided by the Universal Service Provision (USP) and the Community Broadband Library projects under the National Broadband Initiative. Furthermore, this project replaces the traditional method of obtaining reading resources as the computers provided with Internet that offer extensive opportunities for users to search related information. The usage of the internet as a pertinent factor for the rural youth to increase knowledge and directly preparing themselves facing the outside world. For instance, some user will use the internet to send email to the lecturer, connecting friends from another states and also sharing information (picture, videos) thru social media. Hence, this paper will delve the pattern of the internet usage at the rural library among the rural youths.

\section{Methodology}

Based on the literature reviews and past studies, the questionnaire was developed and used as a tool for the data collection. Five Likert-scale (ranging from 1-strongly disagree to 5-strongly agree) had been used to measure the level of usage in the questionnaire excluding the demographic part. After that, a pre-test was conducted on 30 youth users in Kuala Selangor. The process of data collection started in June 2014 and completed in December 2014. 400 respondents were selected via a multi-stage-random sampling to complete the data collection process. The main reason of selecting this sampling technique is because of the funds limitation and time to sample from the larger population. Thus, it will avoid difficulty to the researcher to handle such populations. By cutting it up into smaller groups, it is an essence procedure to subject of random sampling. This form of sampling is valid as long as the groups have low between-group variance.

The actual data collections were conducted in four zones, namely, the East Coast Zone (Terengganu), the Central Zone (Perak), the South Zone (Negeri Sembilan) and the West Coast of Malaysia (Sabah). The data collections were assisted by trained and experienced enumerators, and the process was monitored by the researchers. Descriptive analyses such as the frequency, the percentage and the mean score were performed using SPSS to describe the general data of the study.

\section{Results and Discussion}

Table 1 shows the demographic data of the respondents. Below, the data displayed that the females (63.0 per cent) and the Malays (74.3 per cent) were the main users of rural library and they were the largest ratio among the other races in Malaysia. With regard to gender, according to Subrahmanyam et al. (2001, there were gap between male and female for overall the internet usage. This was an expected result since the female respondents were more prominent in using rural library services (Sbaffi \& Rowley, 2001; Omar et. al, 2014; Mazuki et. al, 2014). They were claimed to spend their leisure time in rural library by reading novels, recipe books and not to forget to surf the internet (Melentieva, 2009). Normally, the female group comprises of housewives. Next, the mean score for age was 24.9 years old, half of the respondents were included in the age group of below 20 years old. During the data collection process, a cluster of students and youth respondents came because of school holiday. The rural library seems to be their favourite place to gather as it has been provided with internet services and an ideal place for discussions. A total of 43.8 per cent of the respondents possessed an education level of at least SPM/MCE/SPMV while only 0.8 per cent were recorded to have never attended school. Slightly more than half of the respondents ( 66.2 per cent) were working and while it was good to know that the mean score for average income per month was recorded to be RM 1,415.44. However, the revelation that some of them (27 per cent) still earn below RM700 per month raised some concerns. Basically, the students and the housewives were more enticed to use the services provided by the rural library. Besides that, Table 1 shows that 52.0 per cent of the 
respondents had a number of household between 4 to 6 people.

Table 1: Demographic factor of the respondents.

\begin{tabular}{|c|c|c|c|}
\hline Factor & Frequency & Percentage & Mean \\
\hline \multicolumn{4}{|l|}{ Gender } \\
\hline Male & 148 & 37.0 & \\
\hline Female & 252 & 63.0 & \\
\hline Age (years) & & & 24.9 \\
\hline$<20$ & 184 & 46.0 & \\
\hline $21-30$ & 93 & 23.3 & \\
\hline$>31$ & 123 & 30.8 & \\
\hline \multicolumn{4}{|l|}{ Races } \\
\hline Malay & 297 & 74.3 & \\
\hline Others & 103 & 25.7 & \\
\hline \multicolumn{4}{|l|}{ Education achievement } \\
\hline Never attended school & 3 & .8 & \\
\hline Primary school & 14 & 3.5 & \\
\hline PMR & 112 & 28.0 & \\
\hline SPM/SPMV & 175 & 43.8 & \\
\hline Skill certificate/STPM & 43 & 10.8 & \\
\hline Diploma & 33 & 8.3 & \\
\hline Degree/Master/PhD & 20 & 5.0 & \\
\hline \multicolumn{4}{|l|}{ Employment status } \\
\hline Working & 135 & 33.8 & \\
\hline Not working & 265 & 66.2 & \\
\hline Income $(n=135)$ & & & RM1,415.44 \\
\hline$<$ RM700 & 27 & 20.0 & \\
\hline RM701-RM1500 & 79 & 58.5 & \\
\hline$>$ RM1501 & 29 & 21.5 & \\
\hline \multicolumn{4}{|l|}{ Number of household } \\
\hline $1-3$ & 62 & 15.5 & \\
\hline $4-6$ & 208 & 52.0 & \\
\hline$>7$ & 130 & 32.5 & \\
\hline
\end{tabular}

\section{Internet Usage at the Rural Library}

As showed below (Table 2), the mean score for internet usage at the rural library was 91.12 minutes. Amazingly, with a mean score of 3.33, the respondent's purpose of using the internet was to search for the latest information on current issues followed with to get information about a certain task/subject $(M=3.22)$. Students and housewives were the majority of the respondents in this study. During school holidays or semester breaks, these respondents came to the rural library to finish their assignments or homework. The rural library is another project that tried to narrow the gap of digital divide between the rural and the urban. By searching current issues, the rural youths were able to increase their awareness and absorb the conditions that happened around them. Moreover, Internet usage can produce a knowledgeable rural community and give them opportunities to have a connection with the world. In fact, youth generation are the most prominent age group that easily learn and adopt to the new features of ICT.

Furthermore, the other purpose of using the Internet in rural libraries was to connect with friends or colleagues through webcam, email or social networking sites. Facebook and Twitter are social networking applications that leads to the sense of social cohesiveness among users. Yet, from the social capital theory, a community with a high sense of 
social capital and a high sense of social cohesion, is one that can work towards achieving a common goal and bring benefits to its members (Griffis and Johnson, 2013).Commonly, the Internet encourage users to utilise online content or sharing of information with others. This portrays that the Internet usage would significantly bridging the loopholes between the rural and urban community.

Apart from that, playing games online recorded the lowest mean score $(M=2.54)$ from the other purposes of using internet. Most of the rural libraries are equipped with a maximum of three computers. Playing games online was a common problem that distressed other users as each users would spend a long time and this situation may lead to the dissatisfaction of other users. Other than that, high speed and coverage of the Internet were needed when playing games. Hence, the existence of telecentres, wireless villages or cybercafés are the adequate place for them to visit because these places have adequate tools and better Internet coverage. Moreover, they must obey the norms of library as to be silent and behave in order to respect other users.

Table 2: The duration of Internet usage at the rural library.

\begin{tabular}{|l|c|c|c|}
\hline Duration & Frequency & Percentage & Mean score \\
\hline$<45$ minutes & 61 & 15.8 & 91.12 \\
\hline $45-90$ minutes & 203 & 52.5 & \\
\hline$>90$ minutes & 123 & 31.8 & \\
\hline
\end{tabular}

Table 3: The purpose of internet usage.

\begin{tabular}{|l|c|}
\hline Purposes & Mean score \\
\hline To obtain the latest information on current issues & 3.33 \\
\hline Connecting through email with the teacher / lecturer / employer & 2.55 \\
\hline Connecting with family members (webcam, email, social networking) & 2.98 \\
\hline Connecting with friends / colleagues (webcam, email, social networking) & 3.12 \\
\hline Getting information about the subject / task & 3.22 \\
\hline Getting information about club activities & 3.02 \\
\hline Getting information about the course of Association / Ministry / University & 2.95 \\
\hline Getting information about the business / entrepreneurship & 2.85 \\
\hline Getting information about politics & 2.59 \\
\hline Using internet applications (online banking / YouTube) & 2.94 \\
\hline Playing games online & 2.54 \\
\hline Sending photo / video & 2.61 \\
\hline Receiving picture / video & 2.67 \\
\hline Getting entertained by watching videos / listening to the music & 2.85 \\
\hline
\end{tabular}

\section{Conclusion}

It was clear that the pattern of internet usage within the rural youths was to get information on current issues. The continuity of the internet usage is crucial for rural youth on apart of retain and facilitate the internet. Apart from this, functional differentiation and specialization, and effective communication processes, among others, would contribute to the adoption of innovations such as the Internet. Other than that, the people dimension of the learning organization was a significant predictor. The results noted that trust and switching costs is another factor affect the pattern of the internet usage among the rural library users. The Internet provides opportunities for socialization (exchange of information).

The digital divide is described as an access problem to Internet resources, which in fact would separate the urban and rural area. However, ambiguity about how to get started on the Internet and how to deal with the complexities of computers may be nearly as important deterrents as economics and lack of access (Katz \& Aspden, 1996) of the users. Efforts to encourage Internet self-efficacy could be achieved by using techniques proven to be effective in other behavioural domains, may be needed to completely close the digital divide. On top of it, our government have made a big strides as far as the adoption and usage of the internet concern. This effort has been seen as the Multimedia Super Corridor (MSC) and the newly launched of High Speed Broadband (HSBB) (Salman, 2010).

This research has the following limitations. First, this research was carried out in Malaysia where the Internet is developing rapidly. Hence, the results needed to be generalized to other developed countries that highly utilizes the Internet. Second, the respondents were mostly those who were unemployed and students. The data might be different in 
terms of purposes of using the Internet at the rural library. However, the user's behaviour was dynamic. Thus a longitudinal research may provide more insights on the pattern of Internet usage among the rural youths in Malaysia.

\section{References}

Ali, S and Mohd, S. H. The Innovation Journal: The Public Sector Innovation Journal, Volume 16(2), 2011, article 6.

Drucker, P. (2001). The guru's guru. Business 2.0, 2(8), 66-72.

Katz, J. E., \& Aspden, P. (1996, October 6).Motivations for and barriers to Internet usage: Results of a national public opinion survey. Paper presented to the 24th annual Telecommunications Policy Research Conference, Solomons, Maryland.

Korgaonkar, P., \& Wolin, L. (1999). A multivariate analysis of Web usage. Journal of Advertising Research, 39, 53-6.

Matthew R. Griffis and Catherine A. Johnson. Social capital and inclusion in rural public libraries: A qualitative approach. Journal of Librarianship and Information Science. (2013)

Mazuki, R., Omar, S.Z., D'Silva, J.L. and Shaffril, H.A.M. Mapping the problems in using the rural library services among rural youth in Malaysia. Proceeding of the Social Sciences Research ICSSR 2014 (e-ISBN 978-967-11768-7-0). 9-10 June 2014, Kota Kinabalu, Sabah, Malaysia. Pg., 156-163.

Melentieva, J.P. (2009). Reading among young Russians: Some modern tendencies. Slavic and East European. Information Resource, 10(4): 304-321.

Omar SZ, Shaffril HAM, Bolong J and D'Silva JL (2012). The impingement factors of rural library services usage among rural youth in Malaysia. Asian Social Science 8(7): 60-68.

Omar, S. Z., Shaffril, H.A.M, D'Silva, J.L. Jusang, B. and Hamzah, A. Mapping the patterns and problems in using rural library services among rural youth in Malaysia. Information Development, 1-12 (2014).

Salman, A. 2010. ICT, the New Media (Internet) and Development: Malaysian Experience. The Innovation Journal: The Public Sector Innovation Journal, 15(1): article 5.

Sbaffi, L,. and Rowley, J.. (2014). Public Libraries and non-users: A comparison between Manchester and Rome. Journal of Librarianship and Information Science, 0(0), 1-13. DOI: 10.1177/0961000613503679.

Subrahmanyam, K., Kraut, R., Greenfield, P. M., \& Gross, E. F. (2001). New forms of electronic media: The impact of interactive games and the Internet on cognition, socialization, and behaviour. In D.L. Singer, \& J.L. Singer (Eds.), Handbook of children and the media (pp. 73 - 99). Thousand Oaks, CA7 Sage Publications.

Vongchavalitkul, B., Singh, P., Neal, A.J. and Morris, M. Group \& Organization Management, Vol. 30 No. 4, August 2005 398-420. DOI: $10.1177 / 1059601103259397$. 